\title{
\#DeleteFacebook: Estudo de caso sobre a dinâmica do uso da hashtag no Twitter
}

Juliana Alcantara ${ }^{1}$

\begin{abstract}
Resumo
O trabalho analisa a dinâmica da hashtag \#DeleteFacebook no Twitter, que alcançou o ranking dos tópicos mais comentados em março de 2018. A etiqueta online surgiu em meio à polémica sobre proteção de dados, quando houve midiatização sobre vazamento de informações envolvendo a empresa de marketing político Cambridge Analytica. O objetivo do estudo é encontrar as principais causas para o desempenho da etiqueta online. A abordagem metodológica é quantitativa e privilegia o método hipotético-indutivo. Consideram-se as possibilidades de que ou influenciadores digitais, ou a mídia tradicional, ou o movimento social tenha sido responsável por condicionar a opinião pública. Os resultados mostram que poucas postagens foram suficientes para um alto alcance da hashtag. A mensagem de maior engajamento é do criador do Whatsapp, Brian Acton, que sensibilizou as audiências ao mesmo tempo que perfis oficias da imprensa norte-americana endossaram o afastamento dos usuários do Facebook.
\end{abstract}

Palavras-chave:

opinião pública; privacidade; Facebook

\begin{abstract}
This article intends to analyze the \#DeleteFacebook dynamics on Twitter. The hashtag reached on Trending Topics in March 2018. The hashtag appeared in a discussion of safe data, just when the media reported about Cambridge Analytica. The politic marketing company is involved on illegal process to get Facebook users information. The objective of the study is to find the main causes for the acting of the hashtag. The methodological approach is quantitative, and it privileges the hypothetical-inductive method. It is considered the possibility that digital influencers, or the traditional media, or the social movement has been responsible for conditioning the public opinion. The results show that few posts were enough for a high reach of the hashtag. The message of greatest engagement belongs to the Whatsapp creator, Brian Acton. He made aware the audiences at the same time as US newspaper profiles endorsed the Facebook user's departure.
\end{abstract}

Keywords:

public opinion; privacy; Facebook

\footnotetext{
${ }^{1}$ Doutoranda em Ciências da Comunicação e Mestra em Jornalismo e Comunicação pela Faculdade de Letras da Universidade de Coimbra (FLUC). alc.juli@gmail.com
} 


\section{VOZES $_{\text {\&IÁLORO }}^{\mid}$}

Itajaí, v. 18, n. 01, jan/jun 2019

\section{Introdução}

Os sites de redes sociais proporcionam uma rápida resposta das audiências a determinados estímulos e acontecimentos, estando eles ligados ao mundo online ou não. "O preço a pagar por esta participação diversificada e disseminada é deixar florescer, simultaneamente, a comunicação espontânea e informal” (CASTELLS, 2011, p. 463).

Nessa transformação de mundo, que Castells chama de Sociedade em Rede, são determinantes fenômenos como globalização, a informacionalização, assim como as teias de riqueza, tecnologia e poder. Essa nova conjuntura, por um lado, faculta a melhoria da capacidade produtiva, criativa e cultural e potencializa a comunicação. Por outro lado, as sociedades estão sendo privadas de direitos políticos. O que configura uma decrescente diminuição da qualidade da democracia e a emergência de poderes autoritários e populistas. “(...) a repentina aceleração do tempo histórico, aliada à abstração do poder em uma rede de computadores, vem desintegrando os mecanismos atuais de controle social e de representação política” (CASTELLS, 1999, p. 93).

O Twitter é um termômetro dos assuntos que estão em pauta. Através dos seus Trending Topics é possível saber quais são os temas mais comentados na rede naquele momento. Essa dinâmica é facilmente observada quando se percebe quais assuntos estão sendo constantemente perscrutados. As notícias geralmente estão no topo dos tópicos mais comentados (CHA et al., 2010).

A polêmica que envolveu o Facebook em meados do mês de março de 2018 no tocante à privacidade de dados é o que motivou esse trabalho. As duas redes sociais sentiram o impacto da reportagem sobre o vazamento de informações de usuários e o uso indevido em ações políticas, nomeadamente as eleições presidenciais norte-americanas (DEUZE, 2012; ZAGO \& BASTOS, 2013).

O objetivo deste estudo é reconhecer o contexto e estudar o processo da hashtag \#DeleteFacebook, que alcançou os Trending Topics mundiais, numa tentativa de encontrar as principais causas para seu alto desempenho. Começamos por explorar o assunto pela perspectiva midiática; desenvolvemos, a seguir, os pressupostos teóricos que dão suporte para a melhor compreensão em termos acadêmicos das hipóteses posteriormente apresentadas. E então, são apresentados e analisados os dados recolhidos do Twitter. Por fim, a conclusão envolve a eleição e o cotejamento das teorias mobilizadas com os dados obtidos. 


\section{VOZES $_{\text {\&IÁLORO }}^{\mid}$}

Itajaí, v. 18, n. 01, jan/jun 2019

\section{O contexto}

No sábado, 17 de março de 2018, o The New York Times², em parceria com o jornal britânico Observer, publicou reportagem que desencadeou uma série de polêmicas em torno do Facebook e da privacidade dos dados dos usuários. A manchete é clara: "How Trump Consultants exploited the Facebook data of millions”. (Em livre tradução: Como os consultores de Trump exploraram dados de milhões no Facebook). O caso já não era novidade. Em dezembro de 2015, o The Guardian já havia divulgado relatórios que provavam a correlação entre o Facebook, dados psicológicos e fins políticos ${ }^{3}$. À época, a empresa prometeu investigar a situação e solucioná-la.

Nada fora feito até então, até que um ex-funcionário da Cambridge Analytica ${ }^{4}$, empresa de marketing político, denunciou a continuação da prática de violação de dados. A companhia participou da corrida eleitoral norte-americana em 2016 trabalhando para Donald Trump, há pelo menos dois anos antes da votação. Durante esse período os dados de 50 milhões de pessoas foram acessados, segundo relatos iniciais - número este que subiu para os 87 milhões 5 .

A empresa foi acusada de ter desenvolvido um software com base nos perfis pessoais dos usuários da rede social e, com as informações recolhidas, ser capaz de explorar, prever e influenciar a escolha dos cidadãos nas urnas. Centenas de milhares de usuários participaram de um teste de personalidade acreditando que estariam auxiliando pesquisas de âmbito acadêmico. Entretanto, o aplicativo, além disso, recolheu dados referentes aos amigos desses usuários no Facebook sem autorização, sem consentimento de nenhuma das partes envolvidas.

Com a divulgação do caso, aconteceram efeitos em cascata. Na bolsa de valores, as ações do Facebook caíram $6.5 \%$, chegando a $16 \%$, o que representou uma perda de cerca de 100 bilhões de dólares em dez dias ${ }^{6}$. Os reflexos chegaram a outras empresas do setor.

\footnotetext{
2 Retirado de: https:/www.nytimes.com/2018/03/17/us/politics/cambridge-analytica-trumpcampaign.html. A versão impressa foi publicada no dia seguinte, no domingo, 18 de março em 2018.

3 Retirado de: https://www.theguardian.com/us-news/2015/dec/11/senator-ted-cruz-presidentcampaign-facebook-user-data

4 A Cambridge Analytica é uma empresa de marketing político que trabalha com marcas e campanhas eleitorais. Foi fundada em 2013 e possui escritórios em Londres, Nova York e Washington. Entre os serviços prestados estão pesquisa de mercado e publicidade segmentada.

5 Retirado de: https://www.publico.pt/2018/04/04/tecnologia/noticia/cambridge-analyticaacedeu-a-dados-de-87-milhoes-de-utilizadores-1809156

6 Retirado de: https://www.bloomberg.com/news/articles/2018-03-26/facebook-headingtoward-worst-month-since-august-2012
} 


\section{VOZES $_{\text {\&IÁLORO }}^{\mid}$}

Itajaí, v. 18, n. 01, jan/jun 2019

A empresa que controla o Google registrou queda de 3\% e nos casos da Amazon, Netflix e Apple a queda alcançou $1.5 \%$.

O movimento \#DeleteFacebook surgiu no Twitter na segunda-feira seguinte à publicação do NYT, 19 de março de 2018. Com isso, foi estimulado que os usuários abandonassem suas contas na rede social e protegessem sua privacidade. O criador do Whatsapp, Brian Acton, foi um dos primeiros a se pronunciar defendendo a ideia do afastamento do Facebook. Ele e Jan Koum, cofundador do aplicativo de mensagens instantâneas, venderam seu negócio para o Facebook por 16 milhões de dólares em $2014^{8}$.

Depois de quatro dias sem se pronunciar, o CEO e fundador do Facebook, Mark Zuckerberg, divulgou uma nota em seu perfil pessoal ${ }^{9}$, em que fala da responsabilidade em proteger os dados dos usuários, da quebra de confiança entre sua empresa e a Cambridge Analytica e anuciou medidas referentes à proteção de dados.

O CEO, em entrevista para a $\mathrm{CNN}$, afirmou que faria o necessário para impedir manipulações nas eleições brasileiras e indianas, que ocorreram em 2018. Não à toa esses dois países foram citados. As maiores audiências da rede social se concentram na Índia (11\%), Estados Unidos (11\%) e Brasil $(6 \%)^{10}$.

Em busca de credibilidade, o Facebook recorreu aos jornais impressos de grande circulação nos Estados Unidos e no Reino Unido ao publicar anúncios publicitários com pedidos de desculpas ${ }^{11}$. Além da ação offline, a tecnologia foi posta a serviço nas páginas pessoais dos usuários. Através de uma ferramenta, foi possível que cada usuário soubesse se seus dados tinham sido disponibilizados para a Cambridge Analytica, quais eram os aplicativos que detinham informações a seu respeito.

O Comitê Judiciário do Senado dos Estados Unidos convidou Mark Zuckerberg a prestar esclarecimentos, o que aconteceu nos dias 10 e 11 de abril de 2018. Assim como o americano, o Parlamento Europeu também o convocou a se pronunciar. Ele foi arguido perante o PE em Bruxelas, em 22 de maio de 2018. Em ambas as vezes, Zuckerberg pediu desculpas.

Em 25 de maio de 2018 entrou em vigor nova Regulamentação Geral de Proteção de Dados da União Europeia, que estabelece multas caso seja descumprida ${ }^{12}$.

\footnotetext{
${ }^{7}$ Retirado de: http://www.bbc.com/portuguese/internacional-43466255

${ }^{8}$ Retirado de: https://oglobo.globo.com/economia/escandalo-de-uso-de-dados-motiva-movimentodeletefacebook-22510458 e https://techcrunch.com/2018/03/20/after-selling-his-company-to-facebookfor-19-billion-brian-acton-joins-deletefacebook/

${ }_{9}$ Retirado de: https://www.facebook.com/zuck/posts/10104712037900071

${ }^{10}$ Retirado de: http://www.b9.com.br/75869/india-se-torna-o-pais-com-maior-numero-de-usuarios-no-facebook/

${ }^{11}$ Retirado de: https://oglobo.globo.com/economia/facebook-recorre-credibilidade-dos-jornais-22529634

12 Retirado de: https://ec.europa.eu/commission/priorities/justice-and-fundamental-rights/data-protection/2018reform-eu-data-protection-rules_pt
} 


\section{VOZES $_{\text {\&IÁLORO }}^{\mid}$}

Itajaí, v. 18, n. 01, jan/jun 2019

\section{Metodologia}

O presente estudo de caso se refere ao uso da hashtag ${ }^{33}$ \#DeleteFacebook que chegou aos Trending Topics dias depois da problematização do uso de dados privados dos usuários da rede social Facebook. O Twitter foi escolhido porque foi a ferramenta usada pelos internautas para se contraporem à primeira e para expressarem sua indignação a Mark Zuckerberg, CEO e um dos fundadores do Facebook.

A pesquisa privilegiou o método hipotético-indutivo para observar os dados recolhidos no Twitter. Uma vez que são comparados grupos através de suposições, surgem pressupostos a serem validados quantitativamente. Esse critério foi escolhido com base nas previsões que apontam um resultado potencial: a capacidade da imprensa em influenciar a opinião pública (CRESWELL, 2009).

São os comportamentos de conjunto que o interessam em primeiro lugar, as suas estruturas e os sistemas de relações sociais que os fazem funcionar e mudar, e não os comportamentos, por si próprios, das unidades que os constituem. Porém, mesmo neste tipo de investigações especificamente sociológicas, as informações úteis, muitas vezes, só podem ser obtidas junto dos elementos que constituem o conjunto (QUIVY \& CAMPENHOUDT, 1992, p. 161).

Parte-se da pergunta-chave "Como se propagou a hashtag \#Deletefacebook?", havendo três possibilidades colocadas como resposta. Consideram-se as hipóteses: (1) movimento social condicionou a opinião pública, (2) influenciadores digitais condicionaram a opinião pública, (3) mídia tradicional condicionou a opinião pública.

A pesquisa foi desenvolvida numa perspectiva quantitativa. A ferramenta online utilizada para a recolha de dados foi a Keyhole ${ }^{14}$. Os dados se referem a três dias - 19 a 21 de março de 2018 -, tendo sido recolhidas as informações no último ao meio-dia.

$\mathrm{Na}$ coleta do dia 21 de março de 2018, que englobou os dois dias anteriores totalizando três dias de análise, foram obtidos 200 tweets de 188 usuários através da ferramenta Keyhole. Esse conteúdo alcançou 6.001.078 impressões (número de vezes que os usuários viram algum post contendo a hashtag em foco; um único usuário pode ser apresentado à hashtag mais de uma vez) e 5.983.901 alcance (número que um único usuário viu a hashtag sendo utilizada).

A amostra considerou os países onde a evidência do uso da hashtag foi maior. Os Estados Unidos concentraram 43,10\% das postagens. Atrás estão a Índia (9,08\%), Canadá (3,83\%), Espanha (2,25\%), Austrália (1,12\%), Brasil (1,53\%), Portugal (0,72\%) e México $(0,55 \%)$.

\footnotetext{
${ }^{14}$ Retirado de: http://keyhole.co
} 


\section{VOZES $_{\text {\&IÁLORO }}^{\mid}$}

Itajaí, v. 18, n. 01, jan/jun 2019

Do conteúdo, $68 \%$ foram retweets, $27 \%$ postagens originais e $5 \%$ respostas. Os cinco usuários que mais influência causaram foram @brianacton, @sruhle, @businessinsider, @independent e @ voxdotcom. Os maiores números de engajamento são determinados pelo número de curtidas e compartilhamentos recebidos nas postagens especificamente que continham a hashtag \#DeleteFacebook.

\section{Conceitos de análise}

Começaremos por explorar o sentido central de 'opinião pública', já que este conceito é atribuído nas três hipóteses a serem perseguidas pelo percurso desta investigação. A seguir prosseguimos a exploração dos conceitos já referidos.

Usada no sentido filosófico, a palavra 'público' designa os conhecimentos disponíveis a qualquer pessoa e que não sejam pertencentes à esfera pessoal. Era esse o viés de pensamento de Kant, que denominava 'público' aquilo a que todos poderiam participar de forma igual e que poderia ser expresso pela linguagem (ABBAGNANO, 2007).

Na contemporaneidade, esse conceito ganha novos contornos com a internet. "O desenvolvimento de uma opinião pública informada pelos media desempenha um papel determinante na definição de direitos políticos, do pluralismo e na criação de uma esfera pública” (CARDOSO, 2014, p. 402). Por essa ótica, o conceito de equivalência, de igualdade, de reciprocidade, de mão-dupla, quase que desaparece ao manter as mídias como influenciadoras inquestionáveis.

A mobilização social online surge, então, contrapondo a ideia de que o público é passivo. Cardoso (2014, p. 410) acomoda o pensamento de Castells em suas palavras: “a internet converte-se num instrumento dinâmico de troca social, onde há burocratização e política estritamente mediática de representação dos cidadãos, a internet é simplesmente um painel de anúncios”.

Nem neste caso os meios de comunicação se apagam, uma vez que os agentes políticos, os movimentos sociais e os cidadãos se utilizam da capacidade de difundir informações e influenciar opções (CASTELLS, 2013). A mídia e a sociedade empregam forças que tendem para um lado do discurso. Tais forças ganham extensões de inconsciente coletivo.

O movimento social é apresentado por Castells (idem, p. 95) como "sintomas de nossas sociedades, e todos causam impacto nas estruturas sociais, em diferentes graus de intensidade e resultados distintos que devem ser determinados por meio de pesquisas”.

Para o autor, os movimentos sociais estão ligados a emoção e sua insurgência não está ligada a uma estratégia política. Pode ser que tal surja posteriormente e, geralmente, com o aparecimento de um líder. Porém, e de qualquer modo, os movimentos sociais têm 


\title{
VOZES! \\ ¿DIÁl DCo
}

Itajaí, v. 18, n. 01, jan/jun 2019

início a partir de pressupostos psicológicos (raiva, medo, esperança, indignação) que são expostos, estimulados, mobilizados e geridos através da internet.

\begin{abstract}
As características dos processos de comunicação entre os indivíduos envolvidos no movimento social determinam as suas características: quanto mais a comunicação for interativa e auto configurável, menos hierárquica é a organização e menos participativo é o movimento. É por essa razão que os movimentos sociais em rede da era digital representam uma nova espécie de movimentos sociais (CASTELLS, 2013, p.33).

É claro que a tecnologia não determina os movimentos sociais ou qualquer outro comportamento social significativo. Mas as redes da internet e dos telemóveis não são apenas instrumentos, mas formas organizacionais, expressões culturais e plataformas significativas para a autonomia política (idem, p.113).
\end{abstract}

Sobre a teoria two-step flow (ou fluxo da comunicação em dois níveis), Wolf (2009) explica ser determinada pela atuação de líderes que influenciam indivíduos pelos meios de comunicação. Dito de outro modo, no processo que gera a formação de opinião pública estão sujeitos que disseminam modos de pensar numa ordem mais complexa que a da influência pessoal. Tal conceito se baseia num ambiente social em que a personalidade do receptor se assenta em seus grupos de referência, como familiares, colegas de trabalho, amigos e religiosos.

$\mathrm{O}$ argumento da midiatização leva em conta que a sociedade vive uma condição moldada pelos meios de comunicação. Tal é a sua influência que não é possível mensurar dos efeitos específicos sobre a cultura nem sobre os indivíduos separadamente (AMPUJA, KOIVISTO \& VÄLIVERRONEN, 2014; DEUZE, 2012).

A proposta do agendamento resume na grande potencialidade que a imprensa tem em sugerir sobre o que pensar, sem ao menos dizer como se deve pensar (Azevedo, 2004). A visibilidade e a projeção que alguns assuntos ganham na mídia de massa permite considerar a teoria do agendamento presente em diversos temas (político, social, de entretenimento, desportivo, econômico, da saúde e em tantos outros).

\section{Análise dos dados recolhidos}

Foram mapeadas poucas postagens considerando o número de alcance da hashtag \#DeleteFacebook. A maioria do conteúdo são repostagens. Isso nos leva a considerar que alguns poucos perfis tiveram relevância em posicionar o assunto entre os mais comentados do Twitter. 


\section{VOZES \\ ¿DIÁl DCo}

Itajaí, v. 18, n. 01, jan/jun 2019

O perfil com mais influência é de um dos fundadores do Whatsapp, que vendeu seu aplicativo para o Facebook. Brian Acton possui 41.9 mil seguidores ${ }^{15}$ e destacou seu tweet com o apelo para se apagar o Facebook em 20 de março. Essa postagem possui 1,9 mil comentários, foi repostada 14.750 vezes e teve 35.555 mil gostos.

Imagem 1

Brian Acton

@brianacton

Seguir

It is time. \#deletefacebook

$20: 00$ - 20 de mar de 2018

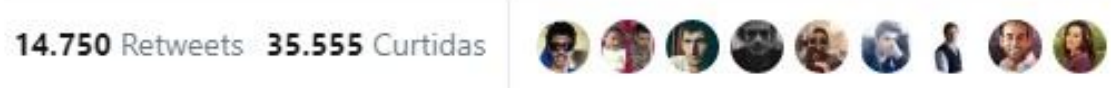

$1,9 \mathrm{mil} \nmid \backslash 15 \mathrm{mil} \bigcirc 36 \mathrm{mil}$

Fonte: Twitter $^{16}$

A segunda conta com mais importância é de Stephanie Ruhle, jornalista da NBC News, que já foi âncora da Bloomberg Television - ambas redes norte-americanas. Ela possui 272 mil seguidores ${ }^{17}$. Em seu tweet (imagem 2), ela cita o Facebook e a Cambridge Analytica. De modo crítico, Ruhle fala que sendo o caso uma violação de dados, é um problema; não o sendo, é um grande problema e reprova a forma com que o Facebook ganha dinheiro. Esse conteúdo somou 185 comentários, 1,9 mil retweets e 4.967 gostos.

\footnotetext{
${ }^{15}$ Dado recolhido em 12 de junho de 2018.

${ }^{16}$ Retirado de: https://twitter.com/brianacton/status/976231995846963201

${ }^{17}$ Dado recolhido em 12 de junho de 2018.
} 


\section{VOZES $_{\text {\&DÁLORO }}^{\mid}$}

Itajaí, v. 18, n. 01, jan/jun 2019

Imagem 2

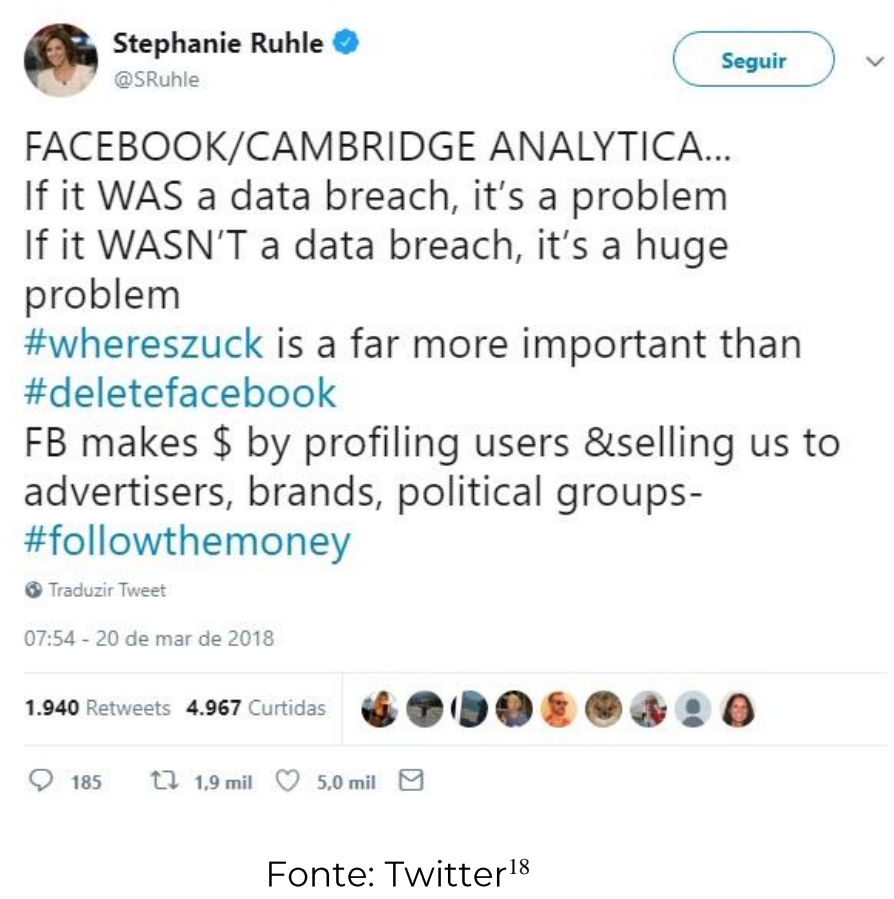

A terceira conta mais influente é a do Business Insider, perfil oficial do site de notícias nova-iorquino, tendo 2,43 milhões de seguidores ${ }^{19}$. A hashtag \#DeleteFacebook foi usada duas vezes pelo perfil, uma em 19 de março e outra em 20 de março. O tweet com mais relevância foi o primeiro, com 181 comentários, 2.828 retweets e 3.249 gostos. A mensagem é direta: "Veja como deletar sua conta no Facebook".

${ }^{18}$ Retirado de: https://twitter.com/SRuhle/status/976049229624901632

19 Dado recolhido em 12 de junho de 2018. 


\section{VOZES \\ ¿DIÁLOGO}

Itajaí, v. 18, n. 01, jan/jun 2019

Imagem 3

\section{BI}

Business Insider

@businessinsider

\section{Seguir}

\#DeleteFacebook is trending: Here's how to delete your Facebook account

read.bi/2ID9igQ

(6) Traduzir Tweet

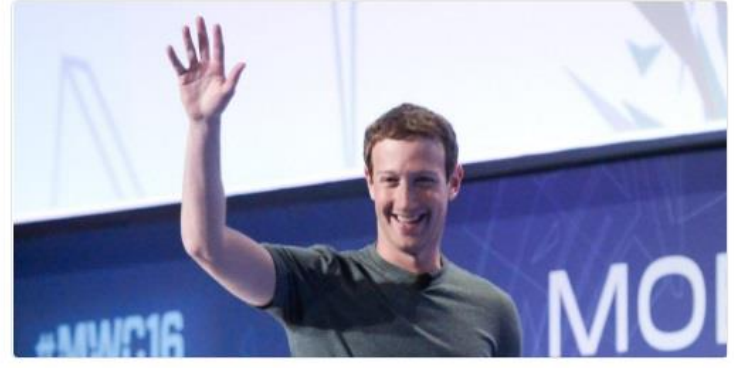

$15: 21$ - 19 de mar de 2018

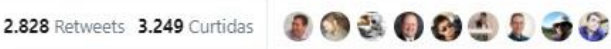

Q 181 t\ 2,8 mil $\bigcirc \quad 3,2$ mil $\quad \square$

Fonte: Twitter $^{20}$

A quarta postagem destacada é também de um veículo de mídia, o jornal The Independent. $\mathrm{O}$ site britânico possui no Twitter 2,53 milhões de seguidores ${ }^{21} \mathrm{e}$ fez menção direta ao fim dos perfis no Facebook. Esse tweet teve 40 comentários, 630 retweets e 797 gostos. 


\section{VOZES $_{\text {\&IÁLORO }}^{\mid}$}

Itajaí, v. 18, n. 01, jan/jun 2019

Imagem 4

\section{The Independent}

@independent

This is how you can \#DeleteFacebook forever

(6) Traduzir Tweet

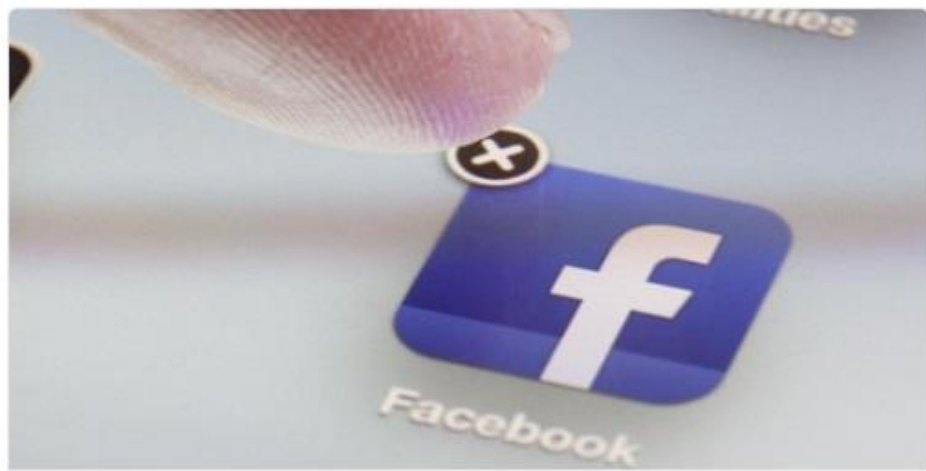

This is how you can delete your Facebook - forever

Social media is great for connecting with people and discovering new content, but for many, it can be a real drag. All those endless notifications, the pressure to post s.

indy $100 . \mathrm{com}$

07:03 - 20 de mar de 2018

630 Retweets 797 curtidas 863

Q $40 \quad$ 4 $630 \quad \bigcirc \quad 797 \quad \square$

Fonte: Twitter 22

Por último, em termos de amostragem, o quinto maior engajamento surgiu na conta da Vox, que possui 726 mil seguidores. O perfil é do site de notícias americano Vox.com. Ao contrário das outras contas de cunho jornalístico, o post aqui referido é neutro. Percebese o intuito informativo sobre o caso que envolveu o Facebook e a Cambridge Analytica. A postagem teve 53 comentários, 967 retweets e 1.246 gostos.

${ }^{22}$ Retirado de: https://twitter.com/Independent/status/976036554799017984 


\section{VOZES $_{\text {\&DÁLORO }}^{\mid}$}

Itajaí, v. 18, n. 01, jan/jun 2019

Imagem 5

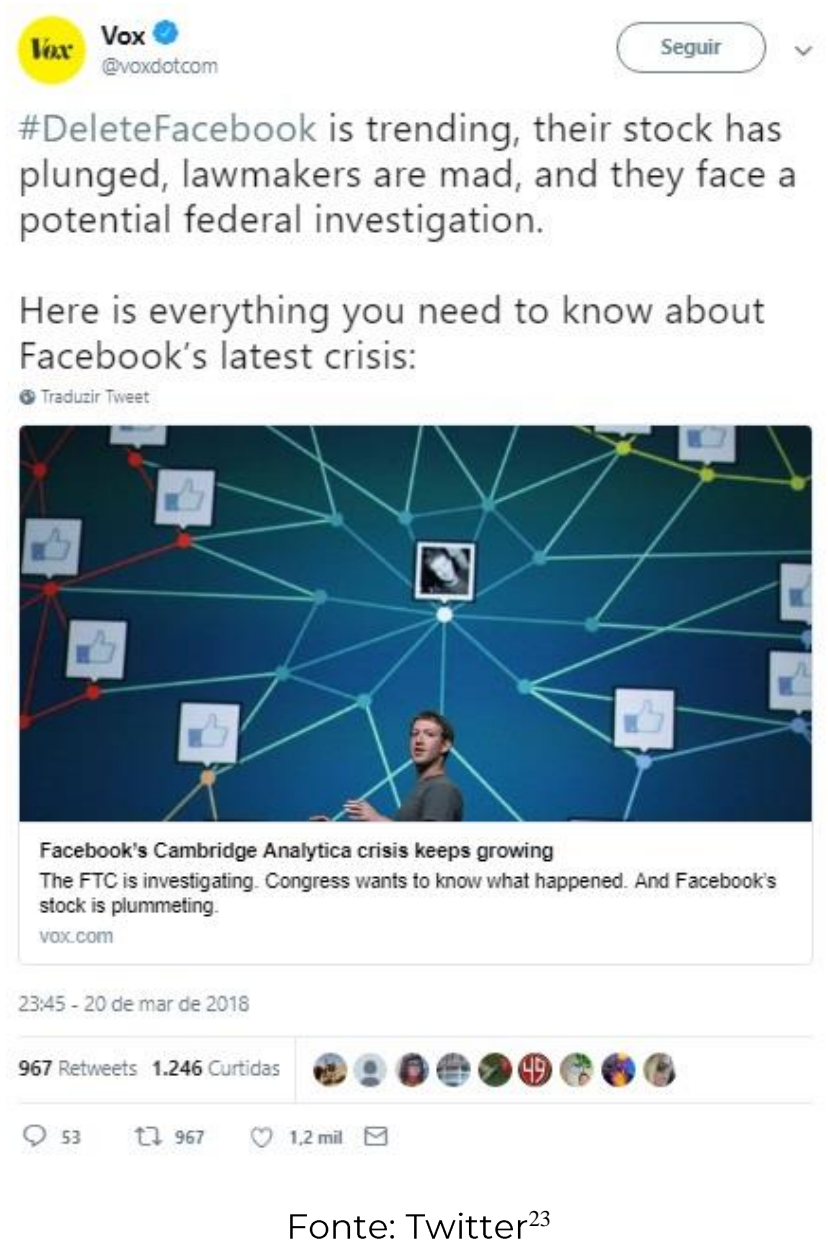

Sobre os países que reuniram maior número de postagem com a hashtag \#DeleteFacebook, é possível relacionar os números com os países que mais usam o Facebook no mundo. Em dados divulgados pela própria empresa em 2017, a Índia ganha destaque sendo o país com maior número de usuários, chegando a ter um milhão a mais que os americanos ${ }^{24}$. Em terceiro lugar em nível de audiência, atrás apenas dos Estados Unidos, está o Brasil. O país é, portanto, o que mais usa o Facebook na América Latina. A seguir estão México e Argentina ${ }^{25}$.

\footnotetext{
${ }^{23}$ Retirado de: https://twitter.com/voxdotcom/status/976288540051963904

${ }^{24}$ Retirado de: https://www.b9.com.br/75869/india-se-torna-o-pais-com-maior-numero-de-usuarios-no-facebook/

${ }^{25}$ Retirado de: https://canaltech.com.br/redes-sociais/brasil-e-o-pais-que-mais-usa-redes-sociais-na-america-latina$\underline{70313 /}$
} 


\section{VOZES $_{\text {\&DÁLORO }}^{\mid}$}

Itajaí, v. 18, n. 01, jan/jun 2019

\section{Conclusão}

A partir das apresentações sobre as hipóteses levantadas (se influenciadores digitais ou a mídia tradicional ou o movimento social foi o responsável por condicionar a opinião pública) e das discussões teóricas em torno do assunto, foi possível analisar os dados recolhidos.

Os resultados apresentados destacam um alto engajamento da hashtag \#DeleteFacebook a partir de 200 tweets postados por 188 usuários. Comparando com o total de impressões (mais de seis milhões) é possível dizer que poucos perfis foram capazes de posicionar a hashtag entre os Trending Topics do Twitter.

Os dados apontaram cinco perfis que mais influenciaram esta dinâmica, todos são americanos. Apesar da conta de Brian Acton, cofundador do Whatsapp, ser a primeira no ranking de sensibilização das audiências, é fundamental destacar as três empresas de mídia dentre as cinco postagens mais engajadas (Business Insider, The Independent, Vox.com).

Com isso, percebe-se que foi imprescindível a capacidade da imprensa em sensibilizar o público. E, como cada empresa já possuía grande número de seguidores (5,68 milhões, totalizando as três contas) foi fundamental a contribuição para que a \#DeleteFacebook alcançasse o topo dos assuntos mais comentados do Twitter no dia 20 de março de 2018.

\section{Referências Bibliográficas}

ABBAGnANO, N. Dicionário de Filosofia. São Paulo: Martins Fontes, 2007.

AMPUJA, M., KOIVISTO, J. \& VALIVERRONEN, E. Strong and Weak Forms of Mediatization Theory A Critical Review. Nordicom Review, 35 Special Issue,111-123, 2014 .

AZEVEDO, F. A. Agendamento da Política. In Antonio Albino \& Canelas Rubim (Org.), Comunicação e Política: Conceitos e abordagens (pp. 41-71). Salvador: Editora UNESP, 2004.

CARDOSO, G. Os Media na Sociedade em Rede. Lisboa: Fundação Calouste Gulbekian, 2014.

Castells, M. A Era da Informação: Economia, Sociedade e Cultura. A Sociedade em Rede Vol.1 4 edição. Lisboa: Fundação Calouste Gulbekian, 2011.

. O Poder da Identidade. Volume II. Tradução Klauss Brandini Gerhardt. São Paulo: Paz e Terra, 1999.

Redes de Indignação e Esperança. Movimentos sociais na Era da Internet. Lisboa: Fundação Calouste Gulbekian, 2013.

CHA, M.; HADDADI, H.; BENEVENUTO, F. \& GUMMAD, K. P. Measuring user influence on twitter: The million follower fallacy. Proceedings of the Fourth 


\section{VOZES $_{\text {\&IÁLORO }}^{\mid}$}

Itajaí, v. 18, n. 01, jan/jun 2019

International AAAI Conference on Weblogs and Social Media, Washington, DC, 10(1017), 30, 2010.

CRESWELL, J. W. Research design. Qualitative and Quantitative Approach. (3 ed) Thousand Oaks: Sage Publications, 2009.

DEUZE, M. Media Life: Digital media and society. Cambridge, UK; Malden, MA: Polity Press, 2012.

QUIVY, R.; CAMPENHOUDT, L. V. Manual de Investigação em Ciências Sociais. Lisboa: Gradiva, 1992.

WOLF, M. Teorias da Comunicação. Lisboa, Presença, 2009.

ZAGO, G. da S; BASTOS, M. T. Visibilidade de Notícias no Twitter e no Facebook: análise comparativa das notícias mais repercutidas na Europa e nas Américas. Brazilian Journalism Research, 9(1), 98-115, 2013. 